\title{
EFEITO DE HERBICIDAS SOBRE A POLIMERIZAÇÃO DOS MICROTÚBULOS E INDUÇÃO DE MICRONÚCLEOS EM PROTOPLASTOS DE Helianthus maximiliani ${ }^{1}$
}

\author{
PEDRO C. BINSFELD², JOSÉ A. PETERS ${ }^{3}$ E HEIDE SCHNABL ${ }^{2}$
}

Institute of Agricultura Botany/University of Bonn, Germany e Departamento de Botânica/Universidade Federal de Pelotas, RS, Brasil

\begin{abstract}
RESUMO - Com o objetivo de estudar a cinética da despolimerização dos microtúbulos e a dinâmica da indução de micronúcleos, usaram-se dois herbicidas com ação antimitótica, amiprofós-metil (APM) e oryzalin (ORY), em células de Helianthus maximiliani. A aplicação de ambos os herbicidas em células com ativo crescimento resultou num elevado número de células com micronúcleos, em virtude das modificações mitóticas causadas pela ausência de microtúbulos. Primeiramente, cromossomos isolados ou grupos de 2 ou mais cromossomos espalharam-se pelo citoplasma. Duas a três horas após a aplicação dos herbicidas, os microtúbulos, estavam despolimerizados e os cromossomos metafásicos condensaram-se, formando diretamente os micronúcleos sem ter havido a divisão do centrômero e a separação das cromátides. A concentração mais eficiente de ORY foi $20 \mu \mathrm{M}$, ao passo que para APM foi $60 \mu \mathrm{M}$, para um período de incubação de 36 e $48 \mathrm{~h}$ respectivamente. O prolongamento do período de tratamento elevou a frequiência de micronúcleos deformados, bem como aumentou a morte celular. A adição de citocalasina-B (CB) $(20 \mu \mathrm{M})$, após $24 \mathrm{~h}$ da aplicação dos herbicidas, aumentou significativamente a micronucleação e estabilização dos micronúcleos nas células. $\mathrm{O}$ controle dos microtúbulos de células em suspensão torna-se uma ferramenta eficiente para a indução de micronúcleos, bem como representa um método elegante para a transferência genômica parcial.
\end{abstract}

TERMOS ADICIONAIS PARA INDEXAÇÃO: Tubulinas, Protoplastos, Amiprofós-methyl, Oryzalin, Girassol

\section{EFFECT OF HERBICIDES ON THE POLYMERIZATION OF THE MICROTUBULE AND INDUCTION OF MICRONUCLEI IN Helianthus maximiliani PROTOPLASTS}

\footnotetext{
ABSTRACT - In order to verify the kinetics of microtubule depolymerization and dynamics of micronuclei induction, two anti-mitotic herbicides, Amiprophos-methyl (APM) and Oryzalin (ORY), were added to dividing cells of Helianthus maximiliani. The addition of both herbicides to actively dividing cells resulted in a high number of cells with micronuclei through modification of mitosis.

Recebido: 3/10/2000 - Aceito: 3/11/2000

1. Este trabalho foi realizado no Institute of Agricultural Botany, Dept. of Plant Physiology and Biotechnology, University of Bonn, Karlrobert-Kreiten-Str. 13, 53115 Bonn, Germany

2. Institute of Agricultural Botany, Dept. of Plant Physiology and Biotechnology, University of Bonn, Karlrobert-Kreiten-Str. 13, 53115 Bonn, Germany

3. Departamento de Botânica, Universidade Federal de Pelotas, Caixa Postal 354, CEP 96010-900, Pelotas, RS, Brasil
} 
Single chromosomes and groups of 2 or more chromosomes were scattered over the cytoplasm. After 2-3 $\mathrm{h}$ of herbicide application, microtubules were depolymerized and the metaphase chromosomes changed directly into micronuclei, without centromere division and chromatid separation. The most efficient concentrations were $20 \mu \mathrm{M}$ ORY and $60 \mu \mathrm{M}$ APM when incubated for 36 and $48 \mathrm{~h}$, respectively. When the treatment duration was increased, the frequency of cells with deformed micronuclei as well as cell death increased. The presence of citochalasina-B (CB) $(20 \mu \mathrm{M})$ after $24 \mathrm{~h}$ of herbicide application increased the frequency of micronucleation and stabilization of the micronuclei in the cells significantly. The control of microtubules using anti-mitotic toxins provides an efficient tool for micronuclei induction as well as representing an elegant method for partial genome transfer.

ADDITIONAL INDEX TERMS: Tubulin, Protoplasts, Amiprophos-methyl, Oryzalin, Sunflower

\section{INTRODUÇÃO}

Microtúbulos (MTs) são filamentos de estrutura subcelular, compostos basicamente pela proteína heterodimérica tubulina (Quader, 1997). Os MTs exercem importantes funções célulares durante o crescimento e ciclo mitótico. Participam em diversos processos relacionados à migração dos cromossomos, estruturação celular, orientação e disposição das microfibrilas de celulose, formação da parede celular, ao movimento intracelular bem como à diferenciação celular (Morejohn, 1991; Jordan e Wilson, 1999). A função dos microtúbulos nos processos subcelulares pôde ser melhor entendida quando foi possível tratar células com toxinas que faziam desaparecer os mesmos. Entre os fatores que mais afetam a ação dos MTs na célula, têm-se os fatores químicos, hormonais, iônicos e gradientes elétricos, ou ainda podem ser afetados por fatores ambientais, tais como temperatura, luminosidade, gravidade e pressão (Quader, 1997; Jordan e Wilson, 1999).

Em estudos básicos sobre microtúbulos de plantas, verificou-se que substâncias tóxicas, como alguns herbicidas ou a colchicina, formam complexos com o dímero da $\alpha$ e $\beta$ tubulina, impedindo sua normal polimerização (Hanser et al., 1998). Entre os agentes antimitóticos, com potente atividade anti-tubulinas, tem-se os herbicidas do grupo dinitroanilina, oryzalin (ORY) e do grupo organofosforado, amiprofós-metil (APM) (Morejohn et al., 1987; Verhoeven et al., 1990; Ramulu et al., 1995). APM e ORY, mesmo em baixas concentrações impedem a polimerização dos microtúbulos inibindo a formação dos fusos cromáticos e induzindo a separação dos cromossomos metafásicos. Esses ficam dispersos por todo o citoplasma, onde condensam formando assim os chamados micronúcleos. Vários micronúcleos sub-diplóides, contendo um ou poucos cromossomos, podem ser visualizados nas células após o tratamento com herbicida (Morejohn et al., 1987; Falconer e Seagull, 1987). Os micronúcleos, por sua vez, representam um considerável potencial para serem usados na transferência genômica parcial, especialmente para transferir características controladas por poligenes, genes desconhecidos ou genes de plantas silvestres para culturas domesticadas. Assim, as barreiras naturais da incompatibilidade sexual podem ser superadas, na busca de introgressão de novos genes através de um processo de hibridação somática assimétrica (Glimelius, 1988; Garriga-Calderé et al., 1998; Binsfeld, 1999).

A indução de micronúcleos, depende fundamentalmente, da eficiência da despolimerização dos microtúbulos da espécie que será usada como genoma doador. Por essa razão, o presente estudo foi delineado com o objetivo de desenvolver um protocolo para indução massal de micronúcleos em protoplastos de Helianthus maximiliani, mediante tratamento com os herbicidas de ação antimitótica APM e ORY.

\section{MATERIAL E MÉTODOS}

O girassol-silvestre Helianthus maximiliani L. proveniente da cultura in vitro (Imhoff et al., 1996), foi utilizado como fonte para o isolamento de protoplastos do mesófilo (Binsfeld 
et al., 1999). Os protoplastos foram cultivados em placas de petri de $5 \mathrm{~cm}$ de diâmetro, em $10 \mathrm{~mL}$ de meio de cultura líquido KMAR (Binsfeld et al., 1999), contendo 5,7 $\mu \mathrm{M}$ de AIA e 4,6 $\mu \mathrm{M}$ de zeatina, a uma densidade de 4,5 x $10^{4}$ protoplastos. $\mathrm{mL}^{-1}$ e incubados em condições de baixa luminosidade $\left(30 \mu \mathrm{mol} \quad \mathrm{m}^{-2} \mathrm{~s}^{-1}\right), \quad$ com fotoperíodo de $16 \mathrm{~h}$ a $26^{\circ} \mathrm{C}$.

Com a finalidade de verificar a dinâmica do crescimento celular, estabeleceu-se a curva de crescimento para protoplastos de $H$. maximiliani. Diariamente, por 9 dias, avaliou-se $1 \mathrm{~mL}$ da cultura de protoplastos, realizando-se a contagem de células em um citômetro de fluxo (Partec CA III). Para a contagem, as células foram lisadas por 6 min com $0,5 \mathrm{~mL}$ de tampão A (Partec $\mathrm{GmbH}$, Münster, Alemanha). Na seqüência, fêz-se a coloração dos núcleos liberados pela adição de 2,0 $\mathrm{mL}$ de solução B (DAPI) em uma cubeta de medição de $5 \mathrm{~mL}$ (Partec $\mathrm{GmbH}$, Münster, Alemanha). Após $10 \mathrm{~min}$, colocou-se a cubeta de medição no citômetro de fluxo para determinar o número de células da cultura. Procedeu-se à análise dos dados com o programa DPAC (Data Pool Application for Cytometry, versão 2.2, Partec $\mathrm{GmbH}$ ).

A determinação do índice mitótico (IM) (número de protoplastos em mitose dividido pelo total de protoplastos observados $\mathrm{x}$ 100) foi feita diariamente por um periodo de 8 dias, analisandose 200 células.

Os agentes antimitóticos utilizados foram, o herbicida amiprofós-metil (APM) ) $[O-$ methyl-O-O-(-4-methyil-6-nitrophenyl)- $N$ isopropyl-phosphoro thioamidate], gentilmente doado pela Bayer Mobay Corporation, Agricultural Chemical Division, Kansas, USA, e o herbicida oryzalin (ORY) $\quad\left(3,5\right.$-dinitro- $N^{4}, N^{4}$ dipropylsulfanilamide), gentilmente doado pela DowElanco Chemicals Corporation, Indianapolis, USA. Com esse material, preparou-se soluções estoque de $65 \mathrm{mM}$ de APM e $60 \mathrm{mM}$ de ORY em dimetil sulfóxido (DMSO) livre de água, que foram estocadas a $-20^{\circ} \mathrm{C}$ para uso posterior (Ramulu et al., 1993).

Para determinar a concentração ideal dos antimitóticos na indução de micronúcleos, em protoplastos de $H$. maximiliani, aplicou-se 0,10 , $20,40,60,90,120 \mu \mathrm{M}$ de APM ou ORY no início do crescimento logarítmico (31/2 dias após o início do cultivo) da cultura de protoplastos. Após 40 h, avaliou-se a formação e o número de micronúcleos em 200 células, para cada nível de tratamento. As células micronucleadas foram contadas, usando-se fotomicroscópio Olympus - BH2 - PM10 - AD.

Para determinar o tempo ótimo de ação dos antimitóticos na indução de micronúcleos, avaliou-se 200 células para cada nível de tratamento, após $0,12,24,36,48,72,96 \mathrm{~h}$ da aplicação do APM $(50 \mu \mathrm{M})$ ou ORY $(20 \mu \mathrm{M})$.

A Citochalasina-B (CB) foi testada sobre a indução, estabilização e manutenção dos micronúcleos. Para isso, 24 h após a aplicação de $50 \mu \mathrm{M}$ de APM e $20 \mu \mathrm{M}$ de ORY, aplicou-se 20 $\mu \mathrm{M}$ de CB (Ramulu et al., 1995). A percentagem de células micronucleadas, sua distribuição e o número de micronúcleos por célula foram determinados 24 h após aplicação de CB em 632 protoplastos tratados com APM e 597 protoplastos tratados com ORY.

As análises foram realizadas em protoplastos corados por $10 \mathrm{~min}$ com uma solução de $10 \mu \mathrm{M}$ de DAPI, em um fotomicroscópio Olympus - BH2 - PM10 - AD. Os experimentos foram repetidos 3 vezes, e os dados obtidos submetidos à análise de significância e à comparação de médias, usando-se o sistema de análise estatística (SANEST) (Zonta et al., 1984).

\section{RESULTADOS E DISCUSÃO}

A eficácia da indução de micronúcleos em células metafásicas depende do antimitótico usado para despolimerizar os microtúbulos, e também da disponibilidade de uma cultura celular que esteja em crescimento ativo e sincronizado. Pela determinação da curva de crescimento (Figura 1) e índice mitótico (Figura 2), foi estimado que a melhor época de aplicação dos antimitóticos está entre o terceiro e quinto dia, por ser a fase exponencial da divisão celular, sendo o tempo de uma geração celular em torno de $30 \mathrm{~h}$. Após o quinto dia, a cultura tendia a uma fase estacionária. 


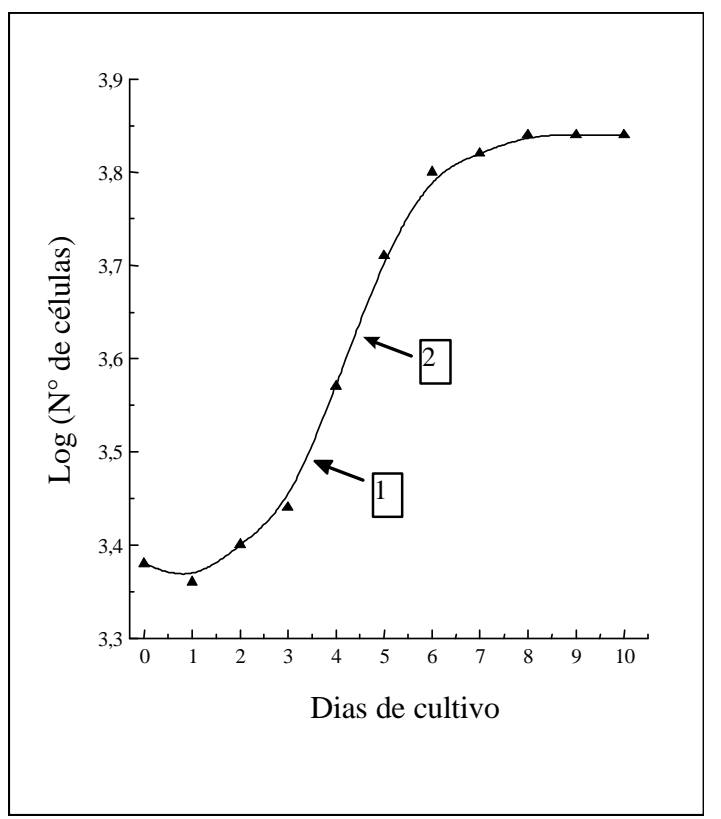

FIGURA 1 - Curva de crescimento dos protoplastos de $H$. maximiliani cultivados em meio de cultura líquido KMAR com 5,7 $\mu \mathrm{M}$ de AIA e 4,6 $\mu \mathrm{M}$ de zeatina. (1) Indica o momento da aplicação dos antimitóticos (APM ou ORY), 31르 dias após o início do cultivo. (2) Indicao momento da aplicação da Citochalasina-B, 24 h após a aplicação dos antimitóticos.

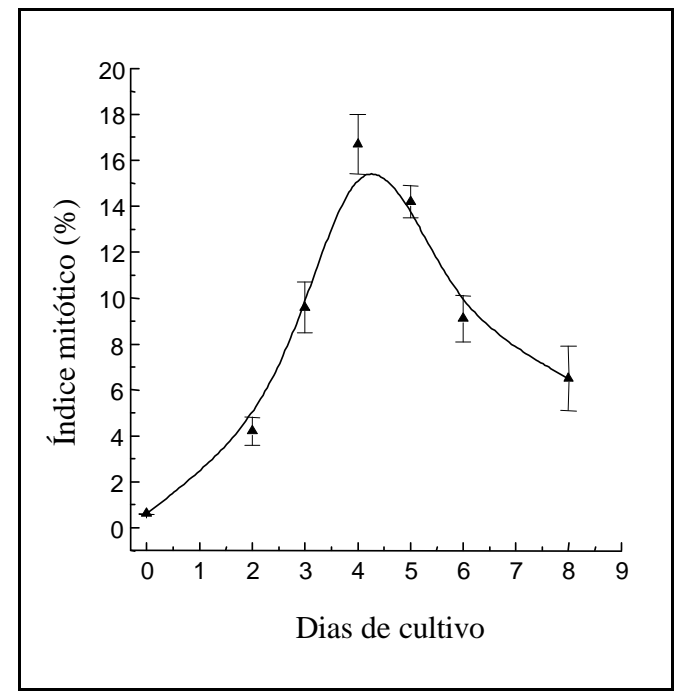

FIGURA 2 - Representação do índice mitótico (IM) de uma cultura de protoplastos de $H$. maximiliani cultivado em meio de cultura líquido KMAR com 5,7 $\mu \mathrm{M}$ de AIA e 4,6 $\mu \mathrm{M}$ de zeatina, no transcorrer de 8 dias de cultivo. Barras verticais indicam o intervalo de confiança para a média estimada ao nível de $95 \%$. 
Para protoplastos de $H$. maximiliani (Figura 2), o índice mitótico mais elevado (17\% das células) foi obtido 4 dias após o início de cultivo. Considerando-se que os antimitóticos necessitam de 6 a $20 \mathrm{~h}$ para induzir os primeiros micronúcleos (Sree et al., 1988), com a aplicação destes $12 \mathrm{~h}$ antes do pico máximo do índice mitótico, obteve-se uma elevação da percentagem de células micronúcleadas.

A micronucleação de células expostas ao APM e ORY envolveu várias etapas (Figura 3), como: despolimerização dos microtúbulos, descondensação dos cromossomos, formação da membrana nuclear e estabilização dos micronúcleos. No tratamento controle, as células mostraram uma divisão mitótica normal, com prófase, metáfase, anáfase e telófase, tendo as mesmas não formado micronúcleos (Figura 3A). Os protoplastos tratados com APM ou ORY, após 2 a $3 \mathrm{~h}$ da aplicação, apresentavam microtúbulos despolimerizados e irregularidades no arranjamento dos cromossomos. Em algumas células formava-se um único agrupamento de cromossomos no centro, ao passo que em outras ocorria a separação dos cromossomos no citoplasma (Figura 3B). Quando os cromossomos estavam distribuídos pela célula, alguns permaneciam isolados, outros formavam pequenos agrupamentos de 2-3 ou mais cromossomos (Figura 3C). A seguir, com a descondensação dos cromossomos metafásicos, iniciou-se a formação de diversos micronúcleos pelo envolvimento dos cromossomos por uma membrana nuclear (Figura 3D). Observou-se que a micronucleação ocorre mediante uma modificação da mitose, na qual os cromossomos metafásicos formam diretamente os micronúcleos, sem que ocorra a divisão do centrômero e a separação das cromátides-irmãs, em virtude da ausência dos microtúbulos. Os eventos acima mencionados corroboram com a descrição feita para espécies de Nicotiana (Verhoeven et al., 1990), Solanum (Ramulu et al.,1995), bem como com a ação da colcemida em células de mamíferos descrita por Fournier et al. (1982).

Os fatores envolvidos na transformação dos cromossomos metafásicos diretamente em micronúcleos, sem separação do centrômero e das cromátides-irmãs (sem anáfase), não são bem conhecidos (Ramulu et al.,1993). Porém, Sree et al. (1988) e Hansen et al. (1998) sugerem que o ORY e o APM podem alterar e desregular a concentração do cálcio na célula, reduzindo a assimilação de cálcio pelas mitocôndrias.

Ambos os herbicidas (APM e ORY) possuem uma potente atividade antitubulinas. Para despolimerizar os microtúbulos, baixas concentrações $(1-20 \mu \mathrm{M})$ podem ser suficientes (Falconer e Seagull, 1987; Quader, 1997), porém, com o incremento da concentração dos antimitóticos (Figura 4), verificaram-se diferentes comportamentos entre o APM e ORY. Enquanto que o ORY mostrou maior indução de micronúcleos na concentração de $20 \mu \mathrm{M}$ (15\% das células com micronúcleos), o APM foi mais eficaz em concentrações mais elevadas $(60 \mu \mathrm{M})$, induzindo micronúcleos em $19 \%$ das células. O ORY, em elevadas concentrações, apresentou maior toxicidade para as células, assim como foi menos eficaz na indução de micronúcleos. Em concentrações superiores a $40 \mu \mathrm{M}$, além de reduzir o número de células com micronúcleos, afetou a viabilidade das células. Em concentração superior a $60 \mu \mathrm{M}$, levou as células rapidamente à morte (Figura 4).

Para células de $H$. maximiliani, a concentração ótima de APM foi $60 \mu \mathrm{M}$ e para ORY foi $20 \mu \mathrm{M}$ (Figura 4), ao passo que Verhoeven et al. (1990), em Nicotiana plumbaginifolia, obtiveram melhor indução com $30 \mu \mathrm{M}$ de ORY e $32 \mu \mathrm{M}$ de APM. Também Sree et al. (1988) mencionaram diferenças nas concentrações usadas para separar cromossomos em $S$. tuberosum e D. carota. Essa variação na resposta pode ser atribuída à diferença na tolerância da cultura aos herbicidas APM ou ORY (Falconer e Seagull, 1987). Em alfafa e alface, a baixa tolerância ao APM no campo estava correlacionada com a alta percentagem da despolimerização dos microtúbulos nas células. A correlação mencionada acima foi também observada em algodão (Falconer e Seagull, 1987), em que a alta tolerância ao APM no campo levou à baixa despolimerização dos microtúbulos nas células. 


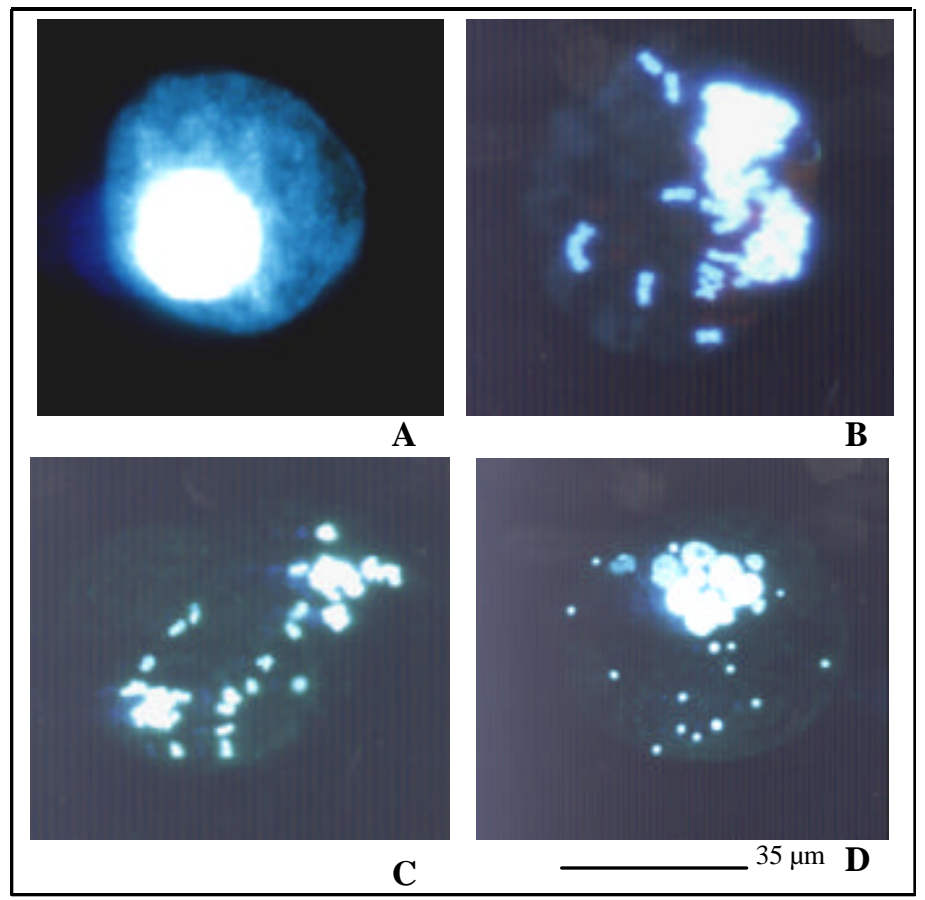

FIGURA 3 - Representação das várias etapas da indução de micronúcleos em células de $H$. maximiliani tratadas com APM e coradas com DAPI. (A) Célula-controle, 4 dias após o início do cultivo em meio de cultura líquido KMAR. DNA da célula corado com DAPI. (B) Célula iniciando a separação dos cromossomos, $15 \mathrm{~h}$ após a aplicação de $50 \mu \mathrm{M}$ de APM. (C) Agrupamento e condensação dos cromossomos, imediatamente antes da formação dos micronúcleos. (D) Célula com micronúcleos de tamanhos variados após o tratamento com $50 \mu \mathrm{M}$ de APM $+20 \mu \mathrm{M}$ de CB.

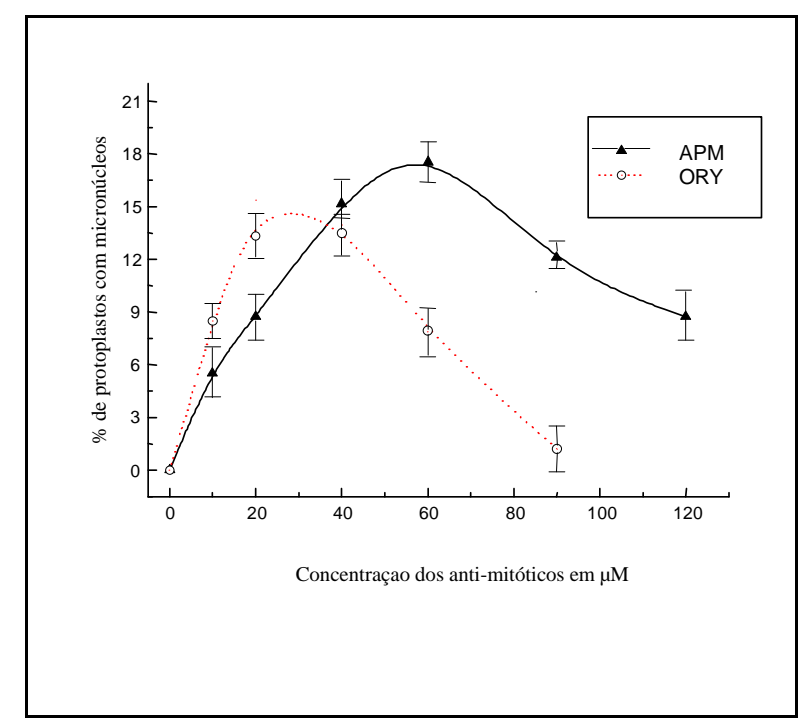

FIGURA 4 - Efeito das diferentes concentrações dos antimitóticos ORY e APM sobre a percentagem da forma-ção de micronúcleos. Barras verticais indicam o intervalo de confiança para a média estimada ao nível de $95 \%$. 
A alta toxicidade observada em células de H. maximiliani ao ORY é atribuida à menor tolerância dessa espécie a esse herbicida. Ao contrário do que se observou para APM, elevadas concentrações de ORY promoveram várias anomalias no processo da indução de micronúcleos. entre elas: deformação dos micronúcleos, formação irregular da membrana nuclear e distúrbios generalizados que conduziam à morte das células. Similar resposta tóxica a altas concentrações foi obtida por Sree et al. (1988), comparando APM e colchicina.

Os micronúcleos grandes, observados em baixas concentrações de antimitóticos são atribuídos a má separação dos cromossomos metafásicos. A despolimerização parcial dos microtúbulos conduz a um menor movimento cromossômico e, em conseqüência, permanecem mais unidos, formando micronúcleos maiores (Ramulu et al., 1993; Jordan e Wilson, 1999).
Em ambos antimitóticos, a duração dos tratamentos influiu na formação dos micronúcleos e na posterior reconstituição de um núcleo único (Figura 5). Verhoeven et al. (1990) e Ramulu et al. (1993) observaram a formação de micronúcleos em células em suspensão num período de 6 a $100 \mathrm{~h}$ após a aplicação de ORY, Cremat, APM ou Colchicina, em diferentes espécies de plantas. Em H. maximiliani, observou-se similar comportamento ao mencionado acima, tendo-se, porém, obtido a máxima eficácia dos antimitóticos entre 36 e 48 h após sua aplicação.

A eficácia da indução de micronúcleos não depende apenas da percentagem de células com micronúcleos, mas também do número de micronúcleos por célula micronucleada. Tanto com APM quanto com ORY, observou-se uma ampla variação do número de micronúcleos por célula. Conforme observa-se na Figura 6, obteve-se uma variação entre 3 e mais de 23 micronúcleos por célula.

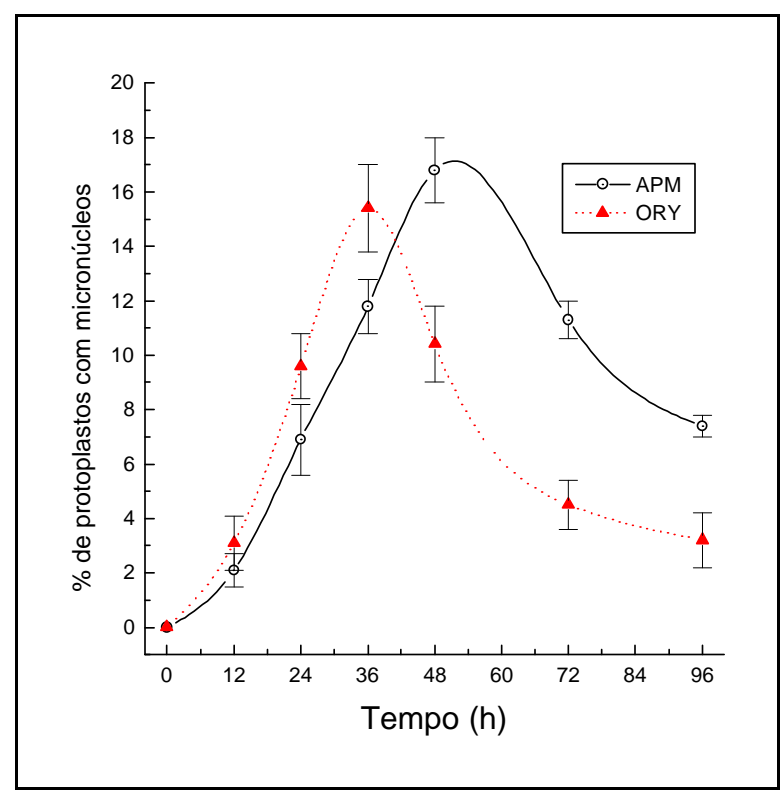

FIGURA 5 - Efeito do período de aplicação dos agentes antimitóticos ORY (20 $\mu \mathrm{M})$ e APM $(50 \mu \mathrm{M})$ sobre a percentagem de formação de micronúcleos. Barras verticais indicam o intervalo de confiança para a média estimada ao nível de $95 \%$. 


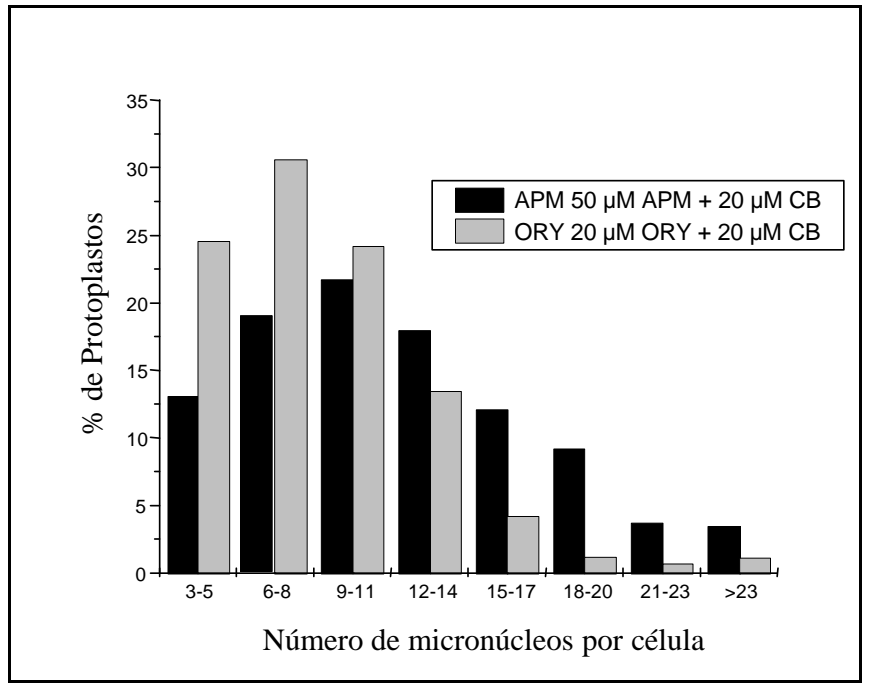

FIGURA 6 - Distribuição em classes do número médio de micronúcleos observados por célula micronucleada, após $48 \mathrm{~h}$ da aplicação dos agentes antimitóticos ORY e APM e 24 h após a aplicação de CB. (ORY, $\mathrm{n}=597$ células; e APM, $\mathrm{n}=632$ células).

A classe com número médio de 6 a 8 micronúcleos por célula foi a mais freqüente para o tratamento com ORY, com $30 \%$ das células micronucleadas. Para o APM, a classe com 9 a 11 micronúcleos por célula foi a mais freqüente, com mais de $20 \%$ das células micronucleadas. No tratamento com ORY, verificou-se que $79,4 \%$ das células com micronúcleos foram distribuídas nas 3 primeiras classes, ao passo que no tratamento com APM havia $53,7 \%$ das células nessas classes. No tratamento com ORY, obteve-se uma média geral de 8,4 micronúcleos por célula. Isso significa que cada micronúcleo é formado, em média, por 3,7 cromossomos, considerando-se que o $H$. maximiliani possua $2 \mathrm{n}=34$ cromossomos. Já no tratamento com APM, obteve-se uma média geral de 11,6 micronúcleos por célula, tendo cada micronúcleo em média 2,8 cromossomos. A aplicação de CB com APM, como mostra a Figura 7, inibiu a reconstituição dos microtúbulos e impediu a restituição dos micronúcleos em um núcleo único. Ramulu et al. (1993) em $N$. plumbaginifolia, observaram 3 a 4 vezes mais células com micronúcleos quando aplicaram $\mathrm{CB}$, 24 h após a aplicação do APM. Em células de $H$. maximiliani, não pôde ser observado esse incremento de 3 a 4 vezes, porém obteve-se o dobro de células micronucleadas em relação ao controle. A aplicação de $\mathrm{CB}$ em células micronucleadas estabilizou os micronúcleos formados e as células que se dividiam lentamente, formando novos micronúcleos, elevando-se, assim, a percentagem de células com micronúcleos, o que concorda com os resultados obtidos por Ramulu et al. (1993). Esses autores observaram ainda que, a aplicação de CB é imprescindível para obter um elevado número de micronúcleos, concordando também com resultados de Ramulu et al. (1995).

Pelos resultados apresentados, concluise que os herbicidas APM e ORY, na presença de $\mathrm{CB}$, são potentes agentes antimitóticos, sendo capazes de despolimerizar rapidamente os microtúbulos promover a indução de elevado número de micronúcleos em protoplastos de $H$. maximiliani. Esse processo mostra-se eficaz quando pretende-se isolar micronúcleos em quantidade suficiente para fusão ou microinjeção com protoplastos receptores, usando-se a técnica dos micronúcleos na transferência genômica parcial. 


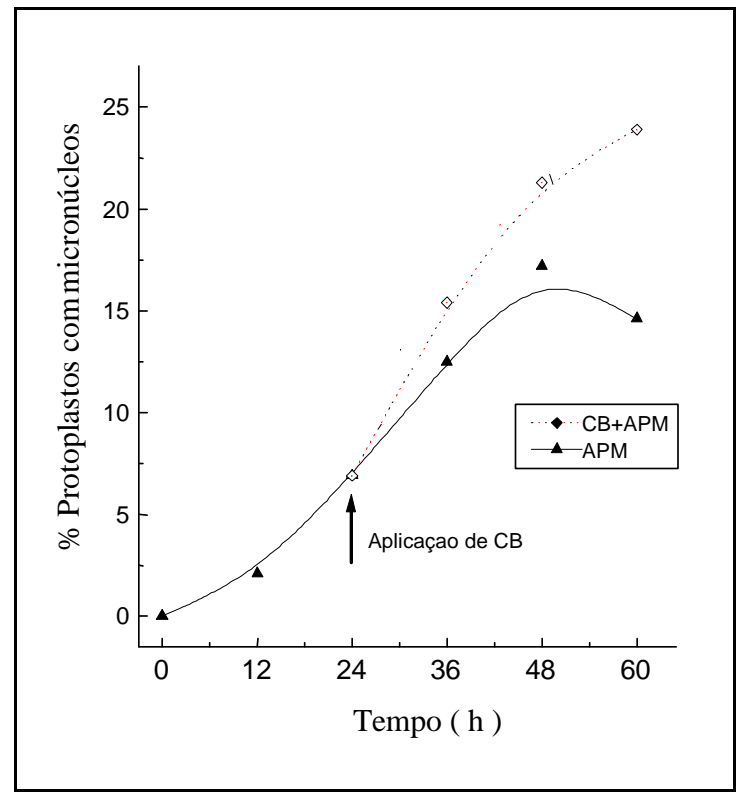

FIGURA 7 - Efeito da aplicação de $20 \mu \mathrm{M}$ de CB sobre a percentagem de células com micronúcleos formados em função do tempo de aplicação de APM + CB.

\section{AGRADECIMENTOS}

Nossos agradecimentos ao $\mathrm{CNPq}$, pelo suporte financeiro, bem como a Bayer Mobay Corporation, USA e DowElanco Chemical Corporation, USA, pela gentil doação dos herbicidas.

\section{REFERÊNCIAS}

BINSFELD, P.C.; WINGENDER, R. \& SCHNABL, H. An optimized procedure for sunflower protoplast (Helianthus ssp.) cultivation in liquid culture. Helia, 22 (30):6170, 1999.

BINSFELD, P.C. Transferência genômica parcial, emprego no melhoramento de plantas. Biotecnologia, 8:86-88, 1999.

De LAAT, A.M.M.; VERHOEVEN, H.A.; SREE RAMULU, K. \& DIJKHUIS, P. Efficient induction by amiprophos methyl and flow cytometric sorting of micronuclei in Nicotiana plumbaginigolia. Planta, 172:473-478, 1987.

FALCONER, M.M. \& SEAGULL, R.W. Amiprophos-methyl (APM): a rapid reversible, anti-microtubule agent for plant cell cultures. Protoplasma, 136:145-124, 1987.

FOURNIER, R.E.K. Microcell-mediated chromosome transfer. In: SHAY, J.W.(Ed.) Techniques in somatic cell genetics, New York, London, Plenum Press, 1982. p.309-327.

GARRIGA-CALDERÉ， F.; HUIGEN， D.J.; ANGRISANO, A.; JACOBSEN, E. \& RAMANNA, M.S. Transmission of alien tomato chromosome from $\mathrm{BC}_{1}$ to $\mathrm{BC}_{2}$ progenies derived from backcrossing potato $(+)$ tomato fusion hybrids to potato: the selection of single additions for seven different tomato chromosomes. Theoretical and Applied Genetics, 96:155-163, 1998. 
GLIMELIUS, K. Potentials of fusion in plant breeding programs. In: PUITE, K.J.; DONS, J.J.M. \& KRENS, F.A. (eds.). Progress in Plant Protoplast Research. Kluwer, Dordrecht. 1988. p.159-168.

HANSEN, N.J.P. \& ANDERSEN, S.B. In vitro chromosome doubling potential of colchicine, oryzalin, trifuluralin, and APM in Brassica napus microspore culture. Euphytica, 88:159164, 1996.

HANSEN, A.L., GERTZ, A., JOERSBO, B. \& ANDESRSEN, S.B. Antimicrotubule herbicide for in vitro chromosome doubling in Beta vulgaris L. ovule culture. Euphytica, 101:231237, 1998.

IMHOFF, U.; WINGENDER, R.; DRESEN, B. \& SCHNABL, H. Micropropagation of three Helianthus wild perennial species. Journal of Applied Botany 70:137-139, 1996.

JORDAN, M.A. \& WILSON, L. The use and action of drugs in analyzing mitosis. Methods in Cell Biology, 61:267-295, 1999.

MOREJOHN, L.C.; BUREAU, T.E.; MOLÉBAJER, J.; BAJER, A. \& FOSKET, D.E. Oryzalin, a dinitroaniline herbicide, binds to plant tubulin and inhibits microtubule polymerization in vitro. Planta, 172:41-147, 1987.

MOREJOHN, L.C. The molecular pharmacology of plant tubuline and microtubules. In: LLOYD C.W. (Ed.) The cytoskeletal basis of plant growth and form. Academic Press, London, 1991. p.29-43.

QUADER, H. Cytoskeleton: Microtubules. Progress in Botany, 59:375-395, 1997.
RAMULU, K.S.; VERHOEVEN, H.A. \& DIJKHUIS, P. Mitotic blocking, micronucleation, and chromosome doubling by oryzalin, amiprophos-methyl and colchicine in potato. Protoplasma, 160:65-71, 1991.

RAMULU, K.S.; DIJKHUIS, P.; FAMELAER, I.; CARDI, T. \& VERHOEVEN, H.A. Isolation of sub-diploid microprotoplasts with for partial genome transfer in plants: enhancement of micronucleation and enrichment of microprotoplasts with one o a few chromosomes. Planta, 190:190-198, 1993.

RAMULU, K.S.; DIJKHUIS, P.; RUTGERS, E.; BLASS, J.; VERBEEK, W.H.J.; VERHOEVEN, H.A. \& COLIJNHOOYMANS, C.M. Microprotoplast fusion technique: a new tool for gene transfer between sexually-incongruent plant species. Euphytica, 85:255-268, 1995.

SREE, K.R.; VERHOEVEN, H.A. \& DIJKHUIS, P. Mitotic dynamics of micronuclei induced by amiprophos-metyl and prospects for chromosome-mediated gene transfer in plants. Theoretical and Applied Genetics, 75:575584, 1988.

VERHOEVEN, H.A.; RAMULU, K.S. \& DIJKHUIS, P.A. comparison of the effects of various spindle toxins on metaphase arrest and formation of micronuclei in cell-suspension cultures of Nicotiana plumbaginifolia. Planta, 182:408-411, 1990

ZONTA, E.P.; MACHADO, A.D. \& SILVEIRA JUNIOR, P. SANEST: Sistema de Análise Estatística para microcomputadores (Software). Pelotas, 1984. 